\title{
AMPC BETA LACTAMASES AMONG GRAM NEGATIVE CLINICAL ISOLATES FROM A TERTIARY HOSPITAL, SOUTH INDIA
}

\author{
Mohamudha Parveen R., Harish B.N., Parija S.C.
}

Department of Microbiology, Jawaharlal Institute of Post Graduate Medical Education and Research, Pondicherry-605006, South India.

Submitted: July 01, 2009; Returned to authors for corrections: December 10, 2009; Approved: March 16, 2010.

\begin{abstract}
AmpC $\beta$-lactamases are cephalosporinases that hydrolyze cephamycins as well as other extended-spectrum cephalosporins and are poorly inhibited by clavulanic acid. Although reported with increasing frequency, the true rate of occurrence of AmpC $\beta$-lactamases in different organisms, including members of Enterobacteriaceae, remains unknown. The present study was designed to determine the occurrence of AmpC enzyme-harbouring Gram-negative clinical isolates in a tertiary care hospital in Pondicherry state, South India. A total of 235 Gram negative clinical isolates were tested for resistance to cefoxitin, third generation cephalosporin (3GC) antibiotics, ampicillin, amikacin, co-trimoxazole, gentamicin, meropenem and tetracycline by disc diffusion method. Isolates found resistant to $3 \mathrm{GC}$ and cefoxitin were tested for the production of AmpC $\beta$-lactamases by three dimensional extraction method and AmpC disc method. Isolates found to sensitive to $3 \mathrm{GC}$ were subjected to disc antagonism test for inducible AmpC production. One hundred and thirty four (57\%) strains were resistant to 3GC, among which $63(47 \%)$ were positive for plasmid-mediated AmpC beta lactamases production. Among the 101 strains sensitive to 3GC, 23 (22.7\%) revealed the presence of inducible AmpC beta lactamases by disc approximation test. A total of $80.9 \%$ (51/63) of screen positive isolates were detected by Amp C disc test and 93.6\% (59/63) by three dimensional extraction method. Out of the 86 AmpC producers, 67 (77.9\%) were cefoxitin resistant .Inducible AmpC was not found in Esch.coli and Klebsiella spp. The AmpC producers also concurrently showed multidrug resistance pattern. AmpC producers were found to be prevalent in our hospital and though three dimensional extraction test detects AmpC better, the disk test is easier to perform routinely and is user- friendly.
\end{abstract}

Key words: Gram negative organisms, drug resistance, three-dimensional technique, AmpC $\beta$-lactamases

\section{INTRODUCTION}

The predominant mechanism for resistance to $\beta$-lactam antibiotics in Gram-negative bacteria is by the synthesis of $\beta$ lactamases (23). Among the $\beta$-lactamases the production of ESBLs and AmpC $\beta$-lactamases are the most common (10).
AmpC $\beta$-lactamases are class $\mathrm{C}$ or group I cephalosporinases that confer resistance to a wide variety of $\beta$-lactam antibiotics including alpha methoxy $\beta$-lactams such as cefoxitin, narrow and broad spectrum cephalosporins, aztreonam, and are poorly inhibited by $\beta$ - lactamase inhibitors such as clavulanic acid (8). Chromosome-mediated AmpC $\beta$-lactamases have been 
described in a wide variety of Gram-negative bacilli, such as Pseudomonas aeruginosa and Enterobacter spp., Acinetobacter spp., Aeromonas spp., C. freundii, E. coli, S. marcescens, etc. Overproduction of their chromosomal AmpC $\beta$-lactamase by mutation is probably responsible for the resistance in these organisms $(13,18)$. In most genera of the family Enterobacteriaceae, AmpC is inducible (8). Unlike chromosome-mediated AmpC, plasmid-encoded AmpC enzymes are almost always expressed constitutively (18) .Many plasmid-mediated AmpC enzymes, such as CMY-type $\beta$-lactamases, have been found in bacterial species that naturally lack a chromosomal AmpC $\beta$-lactamase, such as Klebsiella pneumoniae, Proteus mirabilis, and Salmonella spp. It is believed that such $\beta$-lactamases arose through the transfer of chromosomal AmpC genes onto plasmids. Plasmidmediated inducible $\beta$-lactamases are extremely rare (11).

Several epidemiological studies have shown that AmpC enzyme producing bacteria are recovered from hospitalized patients after several days of admission to the hospital. Affected patients have often had prolonged stay. A majority of patients had been treated with $\beta$-lactam antibiotics including cefoxitin (16). Although it has been over a decade since plasmid-mediated AmpC $\beta$-lactamases were discovered, most clinical laboratories and physicians remain unaware of their clinical importance (2). As a result, organisms producing these types of $\beta$ - lactamases often go undetected and therefore have been responsible for several nosocomial outbreaks (18). Without accurate laboratory detection and reporting of such resistant phenotypes and strains producing plasmid-mediated AmpC, treatment of Gram negative infection may remain suboptimal.

There is a paucity of information on the documentation of AmpC $\beta$-lactamases among Gram negative isolates this region. This is due in part to the lack of standard guidelines for detecting AmpC-producing isolates. Since, the detection of organisms producing these $\beta$-lactamases is thus important; a prospective study was undertaken to determine the occurrence of AmpC $\beta$-lactamases in Gram negative clinical isolates at this centre.

\section{MATERIALS AND METHODS}

\section{Patients and bacterial strains}

This study was carried out in a 750-bedded, urban, tertiary care hospital between May to July 2008. A total of 235 consecutive clinical isolates of $E$. coli $(\mathrm{n}=65), K$. pneumoniae $(\mathrm{n}=38), \quad$ Enterobacter $\quad(\mathrm{n}=26), \quad$ Acinetobacter $\quad(\mathrm{n}=12)$, Pseudomonas $(\mathrm{n}=48)$, Citrobacter $(\mathrm{n}=10)$, Proteus $(\mathrm{n}=31)$, Morganella morganii $(\mathrm{n}=4)$ and Providencia $(\mathrm{n}=1)$ were obtained from various clinical specimens such as blood, urine, sputum, ascitic fluid and pus of hospitalized patients (one isolate per patient). All the isolates were identified biochemically by the standard methods (14) and were stored at $4^{\circ} \mathrm{C}$ in $0.2 \%$ semisolid agar until used.

\section{Antimicrobial susceptibility testing}

The antibiogram of the isolates were determined by the standard Kirby Bauer's disc diffusion method (3). The following antibiotics discs (Hi-Media, India) were used such as, ampicillin $(10 \mu \mathrm{g})$, amikacin $(30 \mu \mathrm{g})$, gentamicin $(10 \mu \mathrm{g})$, co-trimoxazole $(25 \mu \mathrm{g})$, ciprofloxacin $(5 \mu \mathrm{g})$, cefotaxime (30 $\mu \mathrm{g})$, ceftazidime $(30 \mu \mathrm{g})$, ceftriaxone $(30 \mu \mathrm{g})$, cefoxitin $(30 \mu \mathrm{g})$ and meropenem $(10 \mu \mathrm{g})$. The zone diameters were interpreted as per Clinical Laboratory Standards Institute (CLSI) recommendations (9). Escherichia coli ATCC 25922 strain was used for quality control.

\section{Detection of Inducible AmpC Production}

Disc antagonism test (DAT): Isolates that fell in the sensitivity range to cefotaxime, ceftazidime or ceftriaxone (3GC) and cefoxitin as per the CLSI were subjected to disc antagonism test for inducible AmpC detection by the method of Sanders et al. (20).

\section{Detection of Plasmid-mediated AmpC production}

AmpC disk test: Isolates that yielded a cefoxitin zone diameter less than $18 \mathrm{~mm}$ and resistant to $3 \mathrm{GC}$ (screen positive) were tested for $\mathrm{AmpC}$ enzyme production by $\mathrm{AmpC}$ disk test (7). Briefly, 0.5 McFarland suspension of ATCC E. 
coli 25922 was inoculated on the surface of Mueller-Hinton agar plate. A $30 \mu \mathrm{g}$ cefoxitin disc was placed on the inoculated surface of the agar. A sterile plain disc inoculated with several colonies of the test organism was placed beside the cephoxitin disc almost touching it, with the inoculated disk face in contact with the agar surface. After overnight incubation at $37^{\circ} \mathrm{C}$, the plates were examined for either an indentation or a flattening of the zone of inhibition, indicating enzymatic inactivation of cefoxitin (positive result), or the absence of a distortion, indicating no significant inactivation of cefoxitin (negative result).

Modified three-dimensional test: Plasmid-mediated AmpC beta lactamases production was further confirmed by the modified three-dimensional test (15). Briefly, fresh overnight growth of test organism from Mueller-Hinton agar plate was taken in a micro centrifuge tube. Peptone water was added and centrifuged at $3000 \mathrm{rpm}$ for $15 \mathrm{~min}$. Crude enzyme extract was prepared by repeated freeze thawing in $-80^{\circ} \mathrm{C}$ for seven times. A lawn culture of E.coli ATCC 25922 was prepared on MHA plates and cefoxitin $(30 \mu \mathrm{g})$ discs were placed on the plate. Linear slits were cut using a sterile surgical blade $3 \mathrm{~mm}$ away from the cefoxitin disc; 30 to $40 \mu \mathrm{l}$ of the enzyme extract was added to a well made at the outer edge of the slit, without overflowing. The plates were kept upright for 5 to 10 minutes until the liquid dried and were incubated at $37^{\circ} \mathrm{C}$ for overnight. Clear distortion of zone of inhibition of cephoxitin is taken as Amp C beta- lactamase producers.

\section{RESULTS}

\section{Antimicrobial susceptibility testing}

Out of the 235 total isolates tested, 134 (57\%) were resistant to $3 \mathrm{GC}$ (cefotaxime, ceftazidime, ceftriaxone), while $101(42.9 \%)$ strains were susceptible. Majority of the Klebsiella and E.coli and Enterobacter isolates showed multidrug resistance. They were resistant to at least one non- $\beta$ -lactam antibiotic (amikacin, gentamicin, co-trimoxazole, and tetracycline). All of the Providencia and Morganella tested were susceptible to all the antibiotics used. None of the isolates were resistant to meropenem.

\section{Inducible AmpC Production}

Among the 101 sensitive strains, 23 (22.7\%) revealed the presence if inducible AmpC beta- lactamases by disc antagonism test (Fig.1). A maximum number of $42.8 \%$ of Pseudomonas spp. were inducible AmpC producers followed by Enterobacter spp. and Proteus 41.6\%, 31.5\% respectively. None of the E.coli, Klebsiella or Acinetobacter showed inducible AmpC positive. Table 1 shows the distribution of AmpC producers among the different clinical isolates.

\section{Plasmid-mediated AmpC production}

Of the 134 third generation cephalosporin resistant strains, $63(47 \%)$ were positive for plasmid-mediated AmpC beta lactamases. $75 \%$ of Proteus were stable AmpC producers followed by Acinetobacter and Citrobacter $66.6 \%$ each respectively.

Plasmid-mediated AmpC $\beta$-lactamase production was detected in $80.9 \%$ (51/63) of screen positive isolates by Amp C Disc test (Fig.2) and 93.6\% (59/63) by three dimensional enzyme extraction method. Of the 86 total AmpC producers, $67(77.9 \%)$ were cefoxitin resistant and 19 (22\%) were cefoxitin sensitive, shown in table 2.
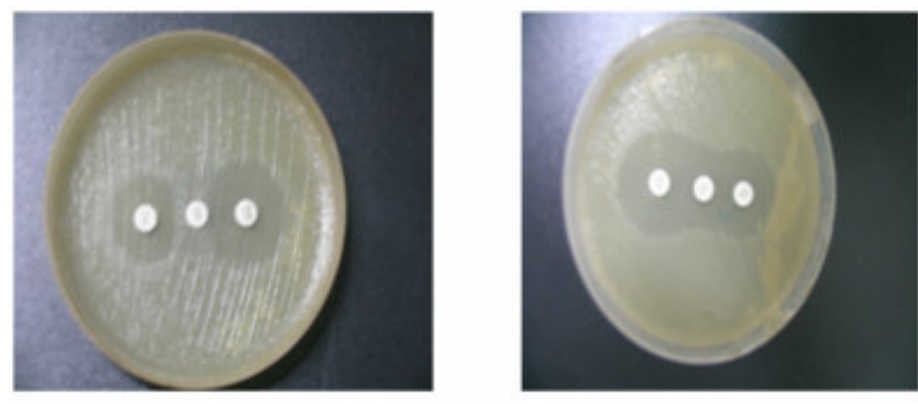

Figure 1. Disk antagonism test. Blunting of the cephalosponin disk adjacent to the cefoxitin disk, positive (A), absence of blunting indicates negative (B). 
Table 1. Prevalence and distribution of AmpC producing Gram negative clinical isolates.

\begin{tabular}{|c|c|c|c|c|c|c|c|}
\hline \multirow[t]{2}{*}{ Organism } & \multirow{2}{*}{$\begin{array}{l}\text { Total No. of } \\
\text { organisms } \\
\text { isolated }\end{array}$} & \multirow{2}{*}{$\begin{array}{l}\text { Isolates } \\
\text { susceptible } \\
\text { to } 3 G C\end{array}$} & \multicolumn{2}{|c|}{ Inducible AmpC } & \multirow{2}{*}{$\begin{array}{l}\text { Isolates } \\
\text { resistant to } \\
\text { 3GC }\end{array}$} & \multicolumn{2}{|c|}{ Plasmid-mediated AmpC } \\
\hline & & & Positive & Negative & & Positive & Negative \\
\hline E.coli & 65 & $22(33.8)$ & - & $22(100)$ & $43(66.1)$ & $11(25.5)$ & $32(74.4)$ \\
\hline Klebsiella & 38 & $15(39.4)$ & - & $15(100)$ & $23(60.5)$ & $9(39.1)$ & $14(60.8)$ \\
\hline Acinetobacter & 12 & $3(25)$ & - & $3(100)$ & $9(75)$ & $6(66.6)$ & $3(33.3)$ \\
\hline Pseudomonas & 48 & $21(43.7)$ & $9(42.8)$ & $12(57.1)$ & $27(56.25)$ & $15(55.5)$ & $12(44.4)$ \\
\hline Enterobacter & 26 & $12(46.1)$ & $5(41.6)$ & $7(58.3)$ & $14(53.8)$ & $9(64.2)$ & $5(35.7)$ \\
\hline Citrobacter & 10 & $4(40)$ & $1(25)$ & $3(75)$ & $6(60)$ & $4(66.6)$ & $2(33.3)$ \\
\hline Proteus & 31 & $19(61.2)$ & $6(31.5)$ & $13(68.4)$ & $12(38.7)$ & $9(75)$ & $3(25)$ \\
\hline Morganella & 4 & $4(100)$ & $1(25)$ & $3(75)$ & - & - & - \\
\hline Providencia & 1 & $1(100)$ & $1(100)$ & - & - & - & - \\
\hline
\end{tabular}

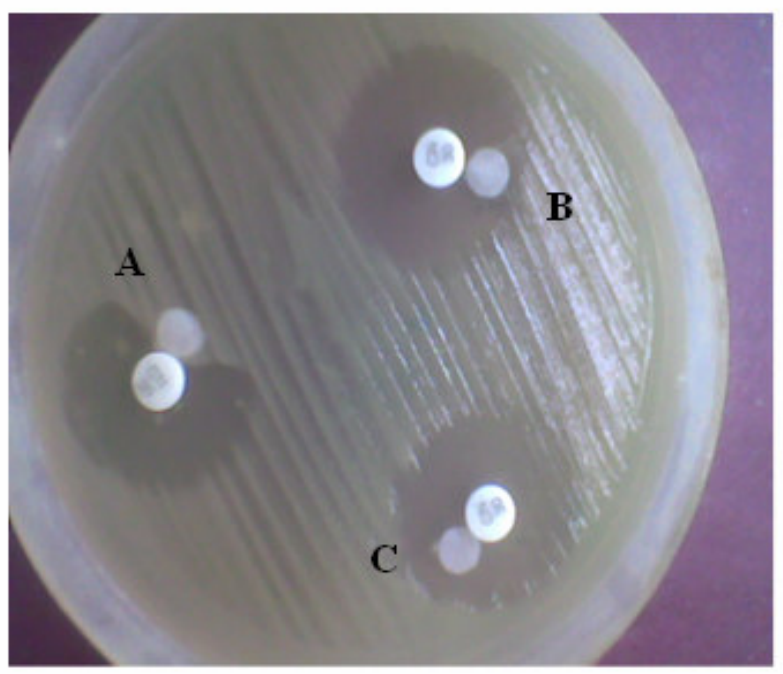

Figure 2. AmpC disk test: Presence of blunting towards cefoxitin disk indicates test positive (A) absence of blunting indicates test negative (B and C).

Table 2. Frequency of cefoxitin resistance among AmpC positive

\begin{tabular}{lcc}
\hline Total AmpC positive isolates (n) & cefoxitin resistant (n) & cefoxitin susceptible (n) \\
\hline E.coli $(11)$ & 9 & 2 \\
Klebsiella $(9)$ & 8 & 1 \\
Acinetobacter $(6)$ & 6 & - \\
Pseudomonas $(24)$ & 18 & 6 \\
Enterobacter $(14)$ & 10 & 4 \\
Citrobacter $(5)$ & 5 & - \\
Proteus $(15)$ & 9 & 6 \\
Morganella $(1)$ & 1 & - \\
Providencia $(1)$ & 1 & - \\
\hline
\end{tabular}




\section{DISCUSSION}

Genes for AmpC $\beta$-lactamases are commonly found on the chromosomes of the several members of the family Enterobacteriaceae, including Enterobacter, Shigella, Providencia, Citrobacter freundii, Morganella morganii, Serratia marcescens and Escherichia coli. Plasmid mediated AmpC $\beta$-lactamases has arisen through the transfer of chromosomal genes for the inducible AmpC $\beta$-lactamases on to plasmids. This transfer has resulted in plasmid mediated AmpC $\beta$-lactamases in isolates of E.coli, Klebsiella pneumoniae, Salmonella species, Citrobacter freundii, Enterobacter aerogenes and Proteus mirabilis (17). Plasmid mediated AmpC $\beta$-lactamases represent a new threat since they confer resistance to cephamycins and are not affected by $\beta$ -lactamase inhibitors, and can, in strains with loss of outer membrane porins, provide resistance to carbapenems. This resistance mechanism has been found around the world, can cause nosocomial outbreaks, appears to be increasing in prevalence, and merits further study to define the best options for detection and treatment (18). Although plasmid-mediated AmpC $\beta$-lactamases were first reported in the late 1980s, many infectious disease personnel remain unaware of their clinical importance. The number of infections caused by AmpC producing organisms is increasing $(4,6,11)$.Distinguishing between AmpC- and ESBL-producing organisms has epidemiological significance and has therapeutic importance as well. Plasmid mediated AmpC $\beta$-lactamases from K.pneumoniae isolates was first reported in 1989 from Seoul, South Korea (5). From US, $6.9 \%$ of K.oxytoca and $4 \%$ of Esch. coli were AmpC producers (1). The prevalence of AmpC $\beta$-lactamases in $K$. pneumoniae was $17.1 \%$, E. Coli $2 \%$ in China (25) DHA-1 type of inducible AmpC $\beta$ lactamases were first reported in Salmonella enteritidis from Saudi Arabia in 1998 (2). Plasmid mediated inducible AmpC $\beta$-lactamases still rare. So far no reports of inducible AmpC among Esch.coli and Klebsiella spp from India also. From North India, $20 \%$ of $P$. aeruginosa (Delhi) and $20.7 \%$ of Gram-negative organisms (Aligarh) and 47.8\% E.coli, $17.3 \%$
P. aeruginosa, $13 \%$ K. pneumoniae (Kolkota) were reported as AmpC $\beta$-lactamase producers $(15,21,22)$. From South Indian states, $24.1 \%$ of Klebsiella spp. and $37.5 \%$ of E. coli were AmpC producers from Chennai; In Karnataka, $3.3 \%$ of E. coli, $2.2 \%$ of $K$. pneumoniae, $5 \%$ of $C$. freundii, and $5.5 \% \mathrm{E}$. aerogenes were found to harbour AmpC enzymes $(24,19)$. In the present study, $22 \%$ of AmpC producers were found to be susceptible to cefoxitin. AmpC production in these isolates could be due a mechanism similar to that of ESBL producing organism that appear susceptible to ceftazidime by the disc diffusion method. They may also have MIC of cefoxitin $<2 \mu \mathrm{g} / \mathrm{ml}$, which was not tested. This finding was similar to a previous study, which reported $39 \%$ of cefoxitin susceptibility in AmpC producers (15).

Cefoxitin resistance in AmpC non-producers could be due to some other resistance mechanism such as, lack of permeation of porins (12). Inducible expression of chromosomal AmpC $\beta$-lactamases, although rare in E. coli and $K$. pneumoniae, is associated with a significant risk of therapeutic failure with all $\tilde{\beta}$ lactam drugs except carbapenems (18). Hence, an attempt was made not to fail to identify inducible strains by DAT. None of the isolates were positive for inducible AmpC $\beta$-lactamase thus revealing the presence of only plasmid mediated resistance in Klebsiella and Esch.coli in them. No resistance to carbapenem was recorded in any of these isolates tested except non-fermentors, which suggests the absence of outer membrane porin defect in them. The 78 (77.2\%) of isolates that showed susceptible to $3 \mathrm{GC}$ and DAT negative were true cephalosporin sensitive strains. Also, 71 (52.9\%) of the AmpC negative 3GC resistance isolates may possess ESBL, which we did not tested. It was found that the sensitivity of the $3 \mathrm{D}$ test is more $(93.6 \%)$ when compared to Amp C Disc test $(80.9 \%)$. There is an increase in sensitivity of $12.7 \%$ with the $3 \mathrm{D}$ test. Amp C disc test is relatively easier to perform when compared to $3 \mathrm{D}$ test. The highest percentage of AmpC-harbouring isolates in clinical specimens from admitted patients thus shows it nosocomial importance. AmpC $\beta$ lactamase producing bacterial pathogens may cause a major therapeutic failure if not detected and reported in time. 
Plasmid-mediated AmpC $\beta$-lactamases have been associated with false in vitro susceptibility to cephalosporins. Thus, the type of $\beta$-lactamase produced by the organism should be detected along with the antibiogram before administering the $\beta$ -lactam drug to the patient. The potential benefits would include better patient outcomes in terms of avoiding inappropriate therapy. Also failure to identify $\mathrm{AmpC} \beta$ lactamase producers may lead to inappropriate antimicrobial treatment and may result in increased mortality. This is alarming and requires urgent action from both a therapeutic and infection control perspective.

In conclusion, this study has revealed the occurrence of AmpC $\beta$-lactamase producing strains of Gram negative isolates for the first time in our region. Occurrence of a large percentage of multidrug resistant strains has been observed. AmpC $\beta$-lactamase production is frequently accompanied by multidrug resistance, thus conjugative dissemination of these AmpC $\beta$-lactamase encoding plasmids is thought to facilitate the spread of resistance against a wide range of antibiotics among different members of Enterobacteriaceae. Meropenem is superior to other antibiotics for the treatment of serious infections due to AmpC $\beta$-lactamase-producing gram-negative bacteria.

\section{REFERENCES}

1. Alvarez, M.; Tran, J.H.; Chow, N.; Jacoby, G.A. (2004). Epidemiology of conjugative plasmid-mediated $\mathrm{AmpC}$ beta lactamases in the United States. Antimicrob Agents Chemother .48, 533-7.

2. Barnaud, G.; Arlet,G.; Verdet,C.; Gaillot,O.;Lagrange, P.H.; Philippon,A. (1998). Salmonella enteritidis: AmpC plasmid-mediated inducible $\beta$-lactamase (DHA-1) with an ampR gene from Morganella morganii. Antimicrob.Agents Chemother. 42, 2352-2358.

3. Bauer, A.W.; Kirby, W.N.; Sherris, J.C.; Truck, H. (1966).Antibiotic susceptibility testing by a standardized single disk method. Am J Clin Pathol .45, 493-6.

4. Bauernfeind, A.; Schneider, I.; Jungwirth, R.; Sahly, H.;Ullmann, U.(1999). A novel type of AmpC $\beta$-lactamase, ACC-1, produced by a Klebsiella pneumoniae strain causing nosocomial pneumonia. Antimicrob. Agents Chemother.43, 1924-1931.

5. Bauernfeind, A.; Chong,Y.; Schweighart, S.(1989). Extended broadspectrum $\beta$-lactamase in Klebsiella pneumoniae including resistance to cephamycins. Infection . 17, 316-21
6. Beringer,W. A.; Hindler, J.; Loeloff, M.; Queenan, A.M.; Lee, N.; Pegues, D.A.; Quinn, J.P.; Bush,K.(2002). Molecular correlation for the treatment outcomes in bloodstream infections caused by Escherichia coli and Klebsiella pneumoniae with reduced susceptibility to ceftazidime. Clin. Infect. Dis. 34,135-146.

7. Black, J.A.; Moland,E.S.;Thomson,K.S.(2005). AmpC Disk Test for Detection of Plasmid-Mediated AmpC $\beta$-Lactamases in Enterobacteriaceae Lacking Chromosomal AmpC $\beta$-Lactamases. J.Clin. Microbiol. 43 (7). 3110-3113.

8. Bush, K.; Jacoby, G.A.; Medeiros, A.A. (1995).A functional classification scheme for $\beta$-lactamases and its correlation with molecular structure. Antimicrob Agents Chemother. 39, 1211-33.

9. Clinical Laboratory Standards Institute (CLSI). (2003). Performance standards for antimicrobial disk susceptibility test. 8th ed. Approved standards, M2-A8, Wayne, Pa(USA).

10. Coudron, P.E.; Moland, E.S. ; Thomson, K.S. (2000). Occurrence and detection of AmpC $\beta$-lactamases among Escherichia coli, Klebsiella pneumoniae and Proteus mirabilis isolates at a veterans medical Center. J Clin Microbiol. 38, 1791-6.

11. Dunne, E.F.; Fey, P.D.; Kludt,P.; Reporter,R.; Mostashari, F.; Shillam, P.; Wicklund, J.; Miller, C.; Holland, B.; Stamey,K.; Barrett, T.J.;Rasheed, J.K.; Tenover, F.C.; Ribot, E.M.; Angulo, F.J.(2000). Emergence of domestically acquired ceftriaxone-resistant Salmonella infections associated with AmpC $\beta$ _-lactamase. JAMA. 284, 3131-3156.

12. Hernandez, A.S; Benedi, V.J.; Martinez, M. L.; Pascual, A.; Aguilar, A.; Tomas.J.M. (1999). Development of resistance during antimicrobial therapy caused by insertion sequence interruption of Porin genes. Antimicrob Agents Chemother .43, 937-9.

13. Jing-Jou Yan; Wen-Chien Ko; Yun-Chih Jung; Chin-Luan Chuang; Jiunn-Jong Wu. (2002). Emergence of Klebsiella pneumoniae Isolates Producing Inducible DHA-1 $\beta$-Lactamase in a University Hospital in Taiwan. J.Clin. Microbiol.40 (9), 3121-3126.

14. Koneman, E.W.; Allen, S.D.; Janda, W.M.; Schreckenberger ,P.C.; Winn, W.C Jr.(1992). The Enterobacteriaceae. In: Color atlas and textbook of diagnostic microbiology, 4th ed. Philadelphia: J.B. Lippincott Co; 105-84.

15. Manchanda, V.; Singh,N.P. (2003). Occurrence and detection of AmpC $\beta$ -lactamases among Gram negative clinical isolates using a modified three-dimensional test at Guru Tegh Bahadur Hospital, Delhi, India. $J$ Antimicrob Chemother. 51, 415-8.

16. Manchanda,V.; Singh,N.P.; Shamweel, A.; Eideh,H.K.; Thukral, S.S.(2006).Molecular epidemiology of clinical isolates of AmpC producing Klebsiella pneumoniae .24 (3),177-81.

17. Medeiros, A.A.; (1997). Evolution and dissemination of $\beta$-lactamases, accelerated by generations of $\beta$-lactam antibiotics. Clin Infect Dis. 24 (1), 19-45.

18. Philippon, A.; Arlet,G.; Jacoby,G.A. (2002). Plasmid-determined AmpC type $\beta$-lactamases. Antimicrob. Agents Chemother. 46, 1-11.

19. Ratna, A.K.; Menon, I.; Kapur, I.; Kulkarni, R. (2003). Occurrence \& 
Parveen, M. et al.

detection of AmpC $\beta$-lactamases at a referral hospital in Karnataka . Indian J Med Res .118, 29-32.

20. Sanders, C.C.; Sanders, W.E.; Goering, H.V. (1982). In vitro antagonism of $\beta$-lactam antibiotics by cefoxitin. J Antimicrob Chemother. 21.968-75.

21. Shahid, M.; Malik, A.; Sheeba.(2003). Multidrug-resistant Pseudomonas aeruginosa strains harbouring R-plasmids and AmpC beta-lactamases isolated from hospitalised burn patients in a tertiary care hospital of North India. FEMS Microbiol Lett .228, 181-6.

22. Suranjana, A.; Manjusri, B.(2005). AmpC $\beta$-lactamase producing bacterial isolates from Kolkata Hospital . Indian J Med Res. 122, 224233
AmpC beta lactamases among Gram negative clinical isolates

23. Susic E.( 2004). Mechanism of resistance in Enterobacteriaceae towards $\beta$ - lactamase antibiotics. Acta Med. Croatica. 58(4), 307-12.

24. Subha, A.; Renuka Devi, V.; Ananthan, S. (2003). AmpC $\beta$-lactamase producing multidrug resistant strains of Klebsiella spp. \& Escherichia coli isolated from children under five in Chennai. Indian J Med Res.117, 13-18.

25. Wang, Q.T.; Liu, Y.M.; Wang, H.; Sun, H.L.; Chen, M.J.; Du, X.L.(2004). Plasmid mediated cephalosporinase among extendedspectrum-beta-lactamase-producing Escherichia coli and Klebsiella pneumoniae. Zhonghua Nei Ke Za Zhi ,43 ,487-490. 